\title{
Project Ecosystem: A global map of mental health research funding
}

\section{Introduction}

M ental illness has a major impact on individuals, healthcare systems and society. Research is needed to improve our understanding of the underlying mechanisms of many mental health conditions and to develop effective treatments. However, the field of mental health research is broad and fragmented. It covers a diversity of health conditions and contains a large and varied population of researchers and funding organisations. These characteristics are a significant challenge to coordinating and conducting research. There has never been, to the best of our knowledge, a comprehensive view of the entire mental health research funding 'ecosystem' at a global scale.

This study provides a snapshot of the mental health research funding ecosystem, showing who the major funders are, what kinds of research they support and how their strategies relate to one another.

\section{Approach}

The study took a bottom-up approach, using the funding acknowledgements on journal papers between 2009 and 2014 to identify the full range of funding organisations supporting mental health research. Alongside this we carried out a survey of researchers to check acknowledgement behaviour and validate the list of funders obtained from the acknowledgement analysis.

There are two caveats to the approach we used to identify mental health papers. First, it will tend to under-represent basic research that did not indicate a clinical relevance to mental health. Second, only half of the 229,980 papers had funding acknowledgements.

To supplement the mapping exercise we produced detailed qualitative profiles of 32 key mental health research funders summarising their current practices and future plans. The data collected was synthesised into six cross-cutting themes covering: attitudes to collaboration; definitions of mental health research; evaluation practices; how funding decisions are made; strategy development; and types of funding.

\section{Findings}

Who are the major mental health research funders?

- The funding acknowledgements on our 229,980 papers revealed 1,908 funders acknowledged on more than 10 papers between 2009 and 2014. These funders came from four sectors: government; not-for-profit; aca-

\section{Summary}

- This study provides an unprecedented map of the global distribution of funding for mental health research built on the funding acknowledgements in over 220,000 research papers published between 2009 and 2014.

- It reveals a diversity of over 1,900 funding agencies supporting mental health research, including private sector organisations and those whose primary remit does not concern mental health.

- Public and not-for-profit funders are the most numerous and include small and relatively new charities.

- The clinical conditions most commonly covered by the research papers were:

1. neurodegenerative and cognition disorders;

2. depressive, anxiety and personality disorders; and

3. substance use and addictive disorders.

- The study also provides detailed profiles of 32 key research funders describing their missions, funding strategies and evaluation approaches, and draws out six themes emerging across these profiles.

demia; and industry. The top 15 funders with the most acknowledgements globally are shown in Table 1.

- Not-for-profit organisations were the most numerous and represented 39 per cent of all funders. Among these we identified a number of small and relatively new charities and foundations, as well as larger organisations whose primary remit does not concern mental health, such as the British Heart Foundation.

- Governments were the most frequently acknowledged source of funding. This sector was cited in 67 per cent of the papers with funding acknowledgements.

- The US was the largest producer of mental health research - 36 per cent of publications - and accounted for 31 per cent of government and not-for-profit funding organisations.

- The highest numbers of mental health research funders were in North America, northern and western Europe, and China. China is dominated by government funding agencies, while some European countries, in particular Finland and Sweden, have relatively more charities and foundations. 
Figure 1: Global mental health research funding

This network represents funders active in mental health research worldwide and relationships between them

The data for the network comes from the 364,324 funding acknowledgements on 229,

funder; the larger the node, the more often that funder has been acknowledged alongside other funders.

The links between nodes indicate the number of times those two funders were acknowledged on the same

paper. Within the global network, some nodes form clusters with many common links; nodes in each clust

are given the same colour and broadly align with the home countries of the funders.

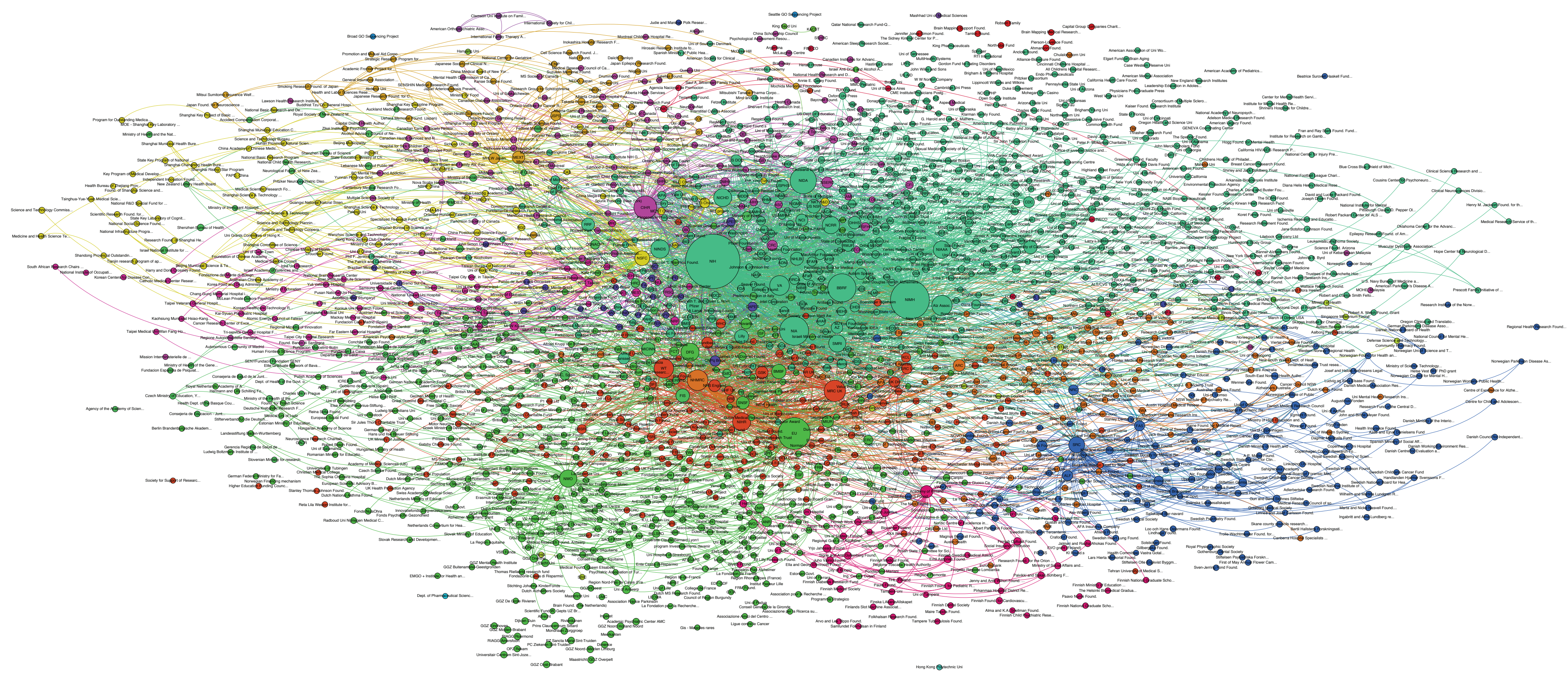




\begin{tabular}{|c|c|c|c|c|c|}
\hline & Funder & $\begin{array}{l}\text { No. of } \\
\text { papers }\end{array}$ & Location & Sector & $\begin{array}{l}\text { Proportion } \\
\text { of papers }\end{array}$ \\
\hline 1 & US National Institutes of Health (NIH) & 16716 & USA & Government & $15 \%$ \\
\hline 2 & National Institute of Mental Health (NIMH) & 10081 & USA & Government & $9 \%$ \\
\hline 3 & National Institute on Drug Abuse (NIDA) & 6231 & USA & Government & $6 \%$ \\
\hline 4 & National Institute on Aging (NIA) & 5266 & USA & Government & $5 \%$ \\
\hline 5 & Canadian Institutes of Health Research (CIHR) & 4701 & Canada & Government & $4 \%$ \\
\hline 6 & Department of Veterans Affairs (VA) & 4387 & USA & Government & $4 \%$ \\
\hline 7 & National Health and Medical Research Council of Australia (NHMRC) & 4033 & Australia & Government & $4 \%$ \\
\hline 8 & European Commission & 4021 & EU & Government & $4 \%$ \\
\hline 9 & National Natural Science Foundation of China (NSFC) & 3836 & China & Government & $3 \%$ \\
\hline 10 & UK Medical Research Council (MRC UK) & 3503 & UK & Government & $3 \%$ \\
\hline 11 & Brain and Behavior Research Foundation (NARSAD) & 3281 & USA & Charity/Foundation/Non-profit & $3 \%$ \\
\hline 12 & Netherlands Organisation of Scientific Research (NWO) & 3112 & Netherlands & Government & $3 \%$ \\
\hline 13 & National Institute for Health Research (NIHR) & 3062 & UK & Government & $3 \%$ \\
\hline 14 & National Institute on Alcohol Abuse and Alcoholism (NIAAA) & 2887 & USA & Government & $3 \%$ \\
\hline 15 & Wellcome Trust & 2434 & UK & Charity/Foundation/Non-profit & $2 \%$ \\
\hline
\end{tabular}

Funding acknowledgements are collated at the most specific funding agency level available. Notably, many papers do not acknowledge a specific NIH institute.

\section{What do they fund?}

- The three clinical conditions with the most papers were neurodegenerative and cognition disorders; depressive, anxiety and personality disorders; and substance use and addictive disorders. Together, papers on these topics comprised 61 per cent of all papers in the dataset.

- Mental health research is loosely defined as a field. The majority of mental health research funders we looked at in depth did not have an explicit definition for mental health.

\section{How do the funders relate to one another?}

- The overall network of co-acknowledgement is shown in Figure 1, which illustrates the complex web of global funding. Funders are coloured in clusters according to their level of co-acknowledgement, so highly connected funders will be the same colour. The fact that colours often align with national boundaries shows that there is more co-funding within, rather than between, countries.

- Papers acknowledging not-for-profit funders tended to have a higher citation impact than papers acknowledging support from funders in other sectors.
What opportunities and challenges might the future hold?

- Funders of mental health research anticipate future or continuing challenges related to: the diversity of the field; difficulty in maintaining funding levels; and the translation of research into practice.

- Opportunities identified by mental health research funders include: increasing collaboration; developing shared definitions; capitalising on government priorities; developing a key role for non-governmental funders; and the advance of technology.

\section{Conclusions}

By using a bottom-up approach, we identified a number of funders who would have been unlikely to appear in a top-down analysis of 'traditional' mental health research funders. In a loosely defined field where funders tend not to define what counts as mental health, we were able to draw on a single standardised data source to map the support for mental health research across the world.

We cross-analysed funding acknowledgements with a range of key variables for each paper, including topic, country, co-authors and number of citations. Our analysis provides a unique resource to help mental health research funders identify potential collaborators working 'in their space', and help them coordinate their efforts.

This brief describes work documented in A. Pollitt, G. Cochrane, A. Kirtley, J. Krapels, V. Larivière, C. Lichten, S. Parks, S. Wooding. Project Ecosystem: A global map of mental health research funding. RAND Report RR-1271-GBF (for more see www.rand.org/pubs/research_reports/RR1271). To view this brief online, visit www.rand.org/pubs/research_briefs/RB9913. RAND Europe is a not-for-profit organisation whose mission is to help improve policy and decisionmaking through research and analysis. RAND Europe's publications do not necessarily reflect the opinions of its research clients and sponsors. RAND $^{\circledR}$ is a registered trademark.

Limited Print and Electronic Distribution Rights: This document and trademark(s) contained herein are protected by law. This representation of RAND intellectual property is provided for noncommercial use only. Unauthorized posting of this publication online is prohibited. Permission is given to duplicate this document for personal use only, as long as it is unaltered and complete. Permission is required from RAND to reproduce, or reuse in another form, any of its research documents for commercial use. For information on reprint and linking permissions, please visit www.rand.org/pubs/permissions.html. 